\title{
Estimativa do teor de fenilalanina em sopas desidratadas instantâneas: importância do nitrogênio de origem não-protéica
}

\author{
Claudia Passos Guimarães, Ursula Maria Lanfer-Marquez* \\ Departamento de Alimentos e Nutrição Experimental, Faculdade de Ciências Farmacêuticas, \\ Universidade de São Paulo
}

*Correspondência:

U. M. Lanfer-Marquez

Depto. de Alimentos e Nutrição

Experimental

FCF-USP

Av. Lineu Prestes, 580

05508-900 São Paulo-SP, Brasil

E-mail: lanferum@usp.br
A análise direta de fenilalanina (Phe) em alimentos com reduzidos teores protéicos destinados a pacientes fenilcetonúricos é difícil, demorada e de alto custo. Emprega-se, geralmente, método indireto baseado na análise do teor protéico bruto, considerando que proteinas naturais contêm ao redor de $4 \%$ de Phe. Neste trabalho estimou-se a concentração de Phe em 22 amostras de sopas desidratadas instantâneas, considerando-se os teores de $N$ total, $N$ protéico e não-protéico e de glutamato monossódico (GMS), que foram analisados independentemente. A concentração de proteína bruta ( $N$ total multiplicado por fator de conversão adequado) variou entre 6,1 e 21,5 g/100 g amostra, apresentando similaridade com os valores protéicos apresentados nos rótulos das sopas. Os teores protéicos reais foram reduzidos e a concentração de Phe calculada a partir desses dados variou entre 51 e $652 \mathrm{mg} / 100 \mathrm{~g}$ amostra. A concentração de GMS nessas amostras foi considerável, sendo que o $N$ proveniente desse realçador de sabor contribuiu com 2,5 a 47,7\% do $N$ total. Concluiu-se que, devido à elevada participação de GMS na formulação das sopas, a estimativa de Phe deve ser precedida de extração prévia de substâncias nitrogenadas não protéicas, para evitar superestimação da proteína e, por conseqüencia, dos teores de Phe. As sopas desidratadas com os menores teores de Phe podem representar uma diversificação no cardápio para fenilcetonúricos.
Unitermos

- Fenilalanina

- Fenilcetonúria

- Nitrogênio não protéico

- Glutamato monossódico

- Sopas desidratadas

\section{INTRODUÇÃO}

A fenilcetonúria (PKU) é uma doença de herança autossômica recessiva, decorrente do erro inato do metabolismo do aminoácido essencial fenilalanina (Phe). Caracteriza-se por uma deficiência no sistema de hidroxilação deste aminoácido, podendo ser causada pela ausência ou redução da atividade da enzima hepática fenilalanina hidroxilase, responsável pela conversão da Phe em tirosina. A deficiência da fenilalanina hidroxilase resulta em níveis tóxicos de Phe no sangue e conseqüente deficiência de tirosina (Champe, Harvey, 1994; Dutra et al., 1986; Acosta 
et al., 1999; Freitas et al., 1999; Mira, Lanfer-Marquez, 2000).

Diagnosticada a PKU, o tratamento é realizado exclusivamente por meio de uma dieta com baixo teor de Phe, com predominância de alimentos de origem vegetal, visando manter os níveis plasmáticos de Phe em concentração próxima à de uma criança saudável normal $(0,99$ $1,32 \mathrm{mg} / \mathrm{dL})$. O tratamento deve ter início nos primeiros meses de vida para evitar o retardo mental, manifestação clínica mais grave da doença. Na ausência de tratamento ou quando o tratamento é iniciado tardiamente, danos graves e irreversíveis no desenvolvimento intelectual e neurológico são inevitáveis. Aparecem entre o terceiro e sexto mês de vida da criança, caracterizando-se por deficiência mental, eczema e hiperatividade (Acosta et al., 1999; Freitas et al., 1999; Mira, Lanfer-Marquez, 2000).

Em alimentos com reduzido teor protéico, a estimativa da concentração de Phe costuma ser feita por cálculo matemático, a partir da concentração de proteína no alimento e da porcentagem de Phe nesta proteína (Lanfer-Marquez, Penteado, 1997). A concentração de Phe na proteína costuma variar entre 3 a 5\% (Bremer et al., 1996), sendo que nenhuma proteína natural é isenta de Phe. Dessa forma, a precisão da estimativa da concentração de Phe depende, primeiramente, da exatidão da análise de proteína.

Inúmeros métodos foram desenvolvidos para determinar a concentração protéica em alimentos. Os métodos diretos baseados em reações colorimétricas, entre eles método de Bradford, Lowry, biureto, ácido bicinchonínico e absorção em ultravioleta (UV) a $280 \mathrm{~nm}$ e os métodos indiretos, como os métodos de Kjeldahl e Dumas, são os mais utilizados para este propósito (Simonne et al., 1997). A espectroscopia de infravermelho próximo é um método alternativo que também vem sendo mais recentemente empregado para estimar o conteúdo protéico de alimentos, tendo se mostrado ferramenta eficiente para controlar a linha de produção industrial de alimentos. Contudo, não é um método apropriado para análises quantitativas precisas (Krishnan et al., 1994; Almendingen et al., 2000).

Os métodos colorimétricos são úteis na determinação de proteínas solúveis, mas não são adequados para alimentos de matrizes complexas contendo ampla variedade de proteínas com solubilidades distintas. Os métodos de Kjeldahl e Dumas são mais empregados para amostras sólidas e são baseados na análise da concentração de nitrogênio, sendo este convertido para proteína por um fator de conversão adequado. O método de Kjeldahl é o método oficial para determinação da concentração protéica a partir da concentração de nitrogênio total sendo, geralmente, o mais utilizado para este propósito (Barreto, 1990; Stockchek, 1990; Simonne et al., 1997).
$\mathrm{Na}$ maioria dos alimentos o $\mathrm{N}$ corresponde aproximadamente a $16 \%$ do peso da proteína, o que implica indiretamente que em $100 \mathrm{~g}$ de proteína tem-se $16 \mathrm{~g}$ de N, e $100 / 16=6,25$, que corresponde ao fator de conversão de nitrogênio:proteína $(\mathrm{N}: \mathrm{P})$. Dessa maneira, quando a concentração de $\mathrm{N}$ total é convertida em proteína utilizando-se o fator de conversão 6,25 , considera-se que todo $\mathrm{N}$ recuperado é proveniente, principalmente, da proteína e que a contribuição de substâncias nitrogenadas não-protéicas, como $\mathrm{N}$ inorgânico (nitrato, nitrito) e outras fontes de $\mathrm{N}$ orgânico (nucleotídeos, ácidos nucléicos, aminoácidos livres, pequenos peptídeos, quitina, clorofila), é desprezível. O fator de conversão N:P 6,25 foi estabelecido por Jones já em 1931, para proteínas da carne que contêm $16 \%$ de nitrogênio em sua constituição e quantidade reduzida de $\mathrm{N}$ não-protéico. Contudo, o fator de conversão 6,25 não pode ser aplicado universalmente a todos os alimentos, pois a porcentagem de nitrogênio na proteína é variável em função da composição em aminoácidos e da presença de nitrogênio de outras origens (Tokoro et al., 1987; Lucas et al., 1988; Mossé, 1990; Sosulski, Imafidon, 1990; Danell, Eaker, 1992; Hernández et al., 1995; Tshinyangu, Hennebert, 1996; Yeoh, Truong, 1996; Salo-Väänänen, Koivistoinen, 1996; Simonne et al., 1997; Lourenço et al., 1998).

O propósito deste trabalho foi estimar a concentração de fenilalanina, a partir do teor protéico, considerando a presença de substâncias nitrogenadas não-protéicas, em sopas desidratadas de diferentes marcas comerciais e diversos sabores. Este estudo se justifica pelo fato destas sopas serem úteis para diversificar o cardápio de pacientes fenilcetonúricos, composto, geralmente, por vegetais.

\section{MATERIAL E MÉTODOS}

\section{Amostras}

As sopas desidratadas instantâneas de diferentes marcas comerciais e diversos sabores, comercializadas em embalagens plásticas revestidas internamente com alumínio, com validade variando entre 10 a 24 meses, foram adquiridas, entre os anos de 2000 e 2003, no comércio local da cidade de São Paulo, e armazenadas em local fresco até o momento da análise. As amostras utilizadas eram de 3 lotes diferentes, sendo cada lote analisado em triplicata.

\section{Preparo das amostras}

As 22 amostras de sopas desidratadas foram pulverizadas uniformemente em moinho analítico Polymix 
Analytical Mill A 10 (Kinematica AG, Luzern, Swiss), acondicionadas em frascos herméticos e armazenadas em local fresco até as análises subseqüentes.

\section{Análises químicas}

A umidade foi determinada de acordo com o método gravimétrico descrito pelo Instituto Adolfo Lutz (1985), por secagem em estufa a $105^{\circ} \mathrm{C}$ durante 4 horas. A concentração de nitrogênio total foi realizada de acordo o método de Kjeldahl (Association of Official Analytical Chemists, 1995) e o resultado multiplicado pelo fator de conversão (Fc) nitrogênio:proteína estabelecido pela Legislação Brasileira (Resolução RDC n. 360 de 23 de dezembro de 2003, da Anvisa), correspondentes a 5,75 para proteínas vegetais, 6,25 para proteínas da carne, soja, milho ou misturas de proteínas e 6,38 para proteínas lácteas.

\section{Determinação do nitrogênio protéico e não-protéico}

A determinação de nitrogênio protéico foi realizada precipitando-se as proteínas com ácido tricloroacético (TCA) a 10\% (Gaines, 1977; Tshinyangu, Hennebert, 1996; Rosenberg, 1996). Os precipitados e sobrenadantes resultantes foram analisados quanto ao teor de nitrogênio pelo método de Kjeldahl (Association of Official Analytical Chemists, 1995).

Em tubo centrífuga de $40 \mathrm{~mL}$ adicionou-se $1 \mathrm{~g}$ de amostra e $10 \mathrm{~mL}$ de TCA, homogeneizando-se a suspensão com auxílio de uma bastão de vidro. O tubo foi colocado em banho-maria com temperatura controlada a $10{ }^{\circ} \mathrm{C}$, sob agitação, por 1 hora. Após este período, o precipitado foi separado por centrifugação a $2500 \mathrm{rpm}$ por 10 minutos, temperatura de $10{ }^{\circ} \mathrm{C}$. O sobrenadante foi removido com auxílio de pipeta de Pasteur. O precipitado foi lavado com mais $10 \mathrm{~mL}$ de TCA $10 \%$, repetindo-se a etapa de centrifugação. Os sobrenadantes combinados foram transferidos para balão volumétrico e o volume ajustado para $50 \mathrm{~mL}$ com água destilada. O precipitado foi quantitativamente transferido para uma placa de Petri, previamente tarada, com auxílio de $20 \mathrm{~mL}$ de solução de éter:etanol (1:1). Após a evaporação da mistura de solvente, o precipitado foi pesado e, em seguida, removido da placa de Petri e homogeneizado. A análise do teor de nitrogênio foi realizada em $100 \mathrm{mg}$ de precipitado e $1 \mathrm{~mL}$ de sobrenadante.

\section{Análise do glutamato monossódico (GMS)}

A análise do glutamato monossódico foi realizada por método potenciométrico em eletrodo sensível à amônia (Biochemicals AS-210 Automated Enzyme Electrode
Analyzer, A\&T), baseado em reação enzimática, em que o ácido L-glutâmico é desaminado na presença da enzima glutamato desidrogenase (Nikolelis, 1987). A extração do glutamato monossódico foi realizada adicionando-se $1 \mathrm{~g}$ de amostra em balão volumétrico de $100 \mathrm{~mL}$, completando-se o volume com água destilada. Foi adicionada 1 gota de $\mathrm{HCl} \mathrm{PA}$ $(1: 2,5 \mathrm{v} / \mathrm{v})$ para prevenir a conversão do ácido glutâmico em pirrolidona. A solução resultante foi filtrada, utilizando-se papel de filtro Whatman $n^{\circ} 41$. O filtrado foi armazenado em frasco hermético, em geladeira, até o momento da análise. $\mathrm{Na}$ célula termostática de reação do equipamento $\left(\mathrm{T}=37 \pm 0,2^{\circ} \mathrm{C}\right)$ foram pipetados $4 \mathrm{~mL}$ de tampão Tris- $\mathrm{HCl} 0,01 M(\mathrm{pH}=8,5)$, $1 \mathrm{~mL}$ de $\beta$-NAD ${ }^{+} 6,0 \times 10^{-3} M$ e $0,2 \mathrm{~mL}$ de solução estoque de L-glutamato desidrogenase (5U)(Sigma Chemical CO., St Louis). O eletrodo sensível à amônia foi imerso na solução da célula termostática, tendo sido necessário aguardar de 1 a 2 minutos até que ocorresse a estabilização do eletrodo. Após a estabilização, foi pipetado $1 \mathrm{~mL}$ do filtrado proveniente da extração do glutamato monossódico. A calibração do equipamento foi realizada seguindo o mesmo procedimento da determinação potenciométrica do glutamato monossódico, utilizando-se a solução estoque de ácido glutâmico (Sigma Chemical CO., St Louis) nas concentrações $0,1 \mathrm{~m} M, 0,5 \mathrm{~m} M$ e 1,0 mM e solução tampão Tris- $\mathrm{HCl} 0,01 M(\mathrm{pH}=8,5)$. Os cálculos foram realizados pelo próprio equipamento que detecta a taxa inicial de potencial da amostra, interpola estes valores com a taxa inicial de potencial do branco e curva padrão e expressa os resultados da concentração da amostra $\left(\mathrm{C}_{\text {equip }}\right) \mathrm{em} \mathrm{mg} / \mathrm{dL}$. A concentração de glutamato monossódico é dada pela equação:

$$
[\mathrm{GMS}]=\frac{\mathrm{C}_{\text {equip }} \times \mathrm{F}_{\mathrm{D}}}{\mathrm{F}_{\text {Conv }}}
$$

onde, $\mathrm{F}_{\mathrm{D}}$ é o fator de diluição e $\mathrm{F}_{\mathrm{Conv}}$ é o fator de conversão ácido glutâmico-GMS, que correspondem, respectivamente, a 100 e 1,2743 .

\section{Leitura espectrofotométrica da solução sobrenadante}

A leitura espectrofotométrica em comprimento de onda a $254 \mathrm{~nm}$ foi realizada em espectrofotômetro (Hitachi U-3410) na solução sobrenadante resultante da precipitação ácida da proteína, previamente filtrada em membrana de filtração com poros de $0,45 \mathrm{~mm}$ da Millipore Corporation (Stockchek, 1990).

\section{RESULTADOS E DISCUSSÃO}

$\mathrm{Na}$ Tabela I, estão apresentados os teores de $\mathrm{N}$ total, proteína bruta $(\mathrm{N}$ totalxFc) e proteína real $(\mathrm{N}$ protéicoxFc) das 22 amostras de sopas desidratadas. Foram utilizados os 
fatores conversão $(\mathrm{Fc})$ nitrogênio:proteína $(\mathrm{N}: \mathrm{P})$ 5,75 para proteínas vegetais, 6,25 para proteínas da carne, soja, milho ou misturas de proteína e 6,38 para proteínas lácteas conforme estabelece a legislação brasileira (Resolução RDC n. 360 de 23 de dezembro de 2003, da Anvisa). Na mesma tabela estão apresentados também os conteúdos em umidade para que todos os resultados pudessem ser expressos em base seca, facilitando comparações com eventuais resultados que forem obtidos no futuro.

Os teores de $\mathrm{N}$ total variaram entre 1,05 e 3,44 g de $\mathrm{N} / 100 \mathrm{~g}$ de amostra, que corresponde à variação entre 6,05 e $21,51 \mathrm{~g}$ de proteína bruta/100 $\mathrm{g}$ de amostra. As sopas à base de ervilha e feijão apresentaram as maiores concentrações de proteína bruta, 21,51 e 18,41 g/100 g, respectivamente. As sopas à base de carne e galinha, com exceção da sopa de galinha com arroz, apresentaram concentrações de proteína bruta intermediárias, variando entre 9,90 e
$14,35 \mathrm{~g} / 100 \mathrm{~g}$. As sopas à base de cebola, creme de batata com mandioquinha e creme de legumes apresentaram os menores teores de proteína bruta, da ordem de 6,05 a $8,98 \mathrm{~g} / 100 \mathrm{~g}$ de amostra. Normalmente, associam-se sopas à base de proteínas de origem animal, tais como de carne, galinha e queijo com os maiores teores de proteína, porém, as sopas à base de leguminosas foram as que apresentaram as concentrações protéicas mais elevadas.

Supondo a presença de quantidades significativas de substâncias nitrogenadas não-protéicas nas sopas, a concentração de fenilalanina (Phe) foi estimada a partir da concentração protéica real. Esta foi determinada subtraindo o $\mathrm{N}$ de origem não-protéica do $\mathrm{N}$ total e multiplicando-se o valor obtido pelo fator de conversão adequado. A concentração de $\mathrm{N}$ de origem exclusivamente protéica foi empregada para calcular a concentração protéica real e a partir desta, estimar a concentração de fenilalanina (Phe).

TABELA I - Composição em umidade, nitrogênio total, proteína bruta ( $\mathrm{N}$ total x Fc) e proteína real ( $\mathrm{N}$ protéico x Fc) de sopas desidratadas instantâneas de diferentes marcas comerciais

\section{Sopas desidratadas}

\begin{tabular}{|c|c|c|}
\hline Umidade $^{1}$ & $\mathrm{~N}$ total $^{1}$ & $\begin{array}{c}\text { Proteína } \\
\text { Bruta }^{1}\end{array}$ \\
\hline
\end{tabular}

(1) Creme batata c/ mandioquinha (Knorr)

(2) Creme cebola (Knorr)

(3) Creme ervilha c/ bacon (Knorr)

(4) Creme milho verde (Knorr)

(5) Creme galinha (Maggi)

(6) Sopa carne c/ macarrão conchinha (Knorr)

(7) Creme Legumes (Knorr)

(8) Sopa galinha c/ fidelini (Knorr)

(9) Sopa galinha c/ arroz (Maggi)

(10) Sopa cebola (Knorr)

(11) Creme queijo (Arisco)

(12) Sopão carne c/ macarrão e legumes (Knorr)

(13) Sopão feijão c/ macarrão e couve (Knorr)

(14) Sopão galinha c/ macarrão e legumes (Knorr)

(15) Canjão galinha c/ arroz e legumes (Knorr)

(16) Sopão carne c/ macarrão e legumes (Arisco)

(17) Canjão galinha c/ arroz e legumes (Arisco)

(18) Sopão galinha c/ macarrão e legumes (Arisco)

(19) Creme de cebola (Arisco)

(20) Creme de cebola (Maggi)

(21) Sopa de cebola (Maggi)

(22) Sopa de cebola (Arisco)

\section{$\mathrm{g} / \mathbf{1 0 0} \mathrm{g}$}

$\begin{array}{cccc}6,19 \pm 0,10 & 1,15 \pm 0,01 & 6,62 \pm 0,02 & 2,51 \pm 0,03 \\ 5,32 \pm 0,36 & 1,07 \pm 0,02 & 6,18 \pm 0,14 & 2,36 \pm 0,03 \\ 6,46 \pm 0,23 & 3,44 \pm 0,03 & 21,51 \pm 0,19 & 16,31 \pm 0,13 \\ 6,08 \pm 0,11 & 1,75 \pm 0,01 & 10,06 \pm 0,07 & 7,02 \pm 0,03 \\ 4,09 \pm 0,10 & 2,30 \pm 0,04 & 14,35 \pm 0,27 & 8,28 \pm 0,01 \\ 6,31 \pm 0,05 & 2,20 \pm 0,02 & 13,74 \pm 0,10 & 8,77 \pm 0,05 \\ 5,88 \pm 0,06 & 1,46 \pm 0,09 & 8,37 \pm 0,50 & 4,30 \pm 0,26 \\ 6,50 \pm 0,14 & 2,29 \pm 0,02 & 14,31 \pm 0,11 & 11,60 \pm 0,21 \\ 5,82 \pm 0,07 & 1,24 \pm 0,04 & 7,76 \pm 0,23 & 5,20 \pm 0,02 \\ 3,89 \pm 0,06 & 1,56 \pm 0,01 & 8,98 \pm 0,03 & 1,48 \pm 0,18 \\ 4,50 \pm 0,02 & 2,05 \pm 0,02 & 13,06 \pm 0,12 & 9,06 \pm 0,04 \\ 6,92 \pm 0,37 & 1,94 \pm 0,01 & 12,10 \pm 0,07 & 8,99 \pm 0,03 \\ 5,19 \pm 0,17 & 2,94 \pm 0,12 & 18,41 \pm 0,73 & 15,55 \pm 0,02 \\ 5,52 \pm 0,27 & 2,07 \pm 0,01 & 12,91 \pm 0,05 & 9,91 \pm 0,08 \\ 7,02 \pm 0,23 & 1,85 \pm 0,03 & 11,57 \pm 0,17 & 8,06 \pm 0,15 \\ 5,63 \pm 0,16 & 2,07 \pm 0,04 & 12,95 \pm 0,26 & 8,61 \pm 0,20 \\ 7,86 \pm 0,15 & 1,58 \pm 0,01 & 9,90 \pm 0,10 & 4,27 \pm 0,01 \\ 9,73 \pm 1,34 & 1,85 \pm 0,01 & 11,55 \pm 0,20 & 8,47 \pm 0,02 \\ 4,43 \pm 0,10 & 1,05 \pm 0,02 & 6,05 \pm 0,11 & 2,96 \pm 0,02 \\ 3,51 \pm 0,18 & 1,44 \pm 0,01 & 8,29 \pm 0,07 & 4,33 \pm 0,01 \\ 3,62 \pm 0,17 & 1,53 \pm 0,06 & 8,82 \pm 0,36 & 4,18 \pm 0,04 \\ 3,23 \pm 0,07 & 1,12 \pm 0,01 & 6,45 \pm 0,01 & 1,28 \pm 0,01\end{array}$

${ }^{1}$ Valores expressos como média \pm desvio padrão $(n=3)$.

$\mathrm{Fc}=$ fator de conversão nitrogênio:proteína estabelecido pela legislação brasileira (6,25 para proteínas da carne, soja, milho ou misturas de proteína, 5,75 para proteínas vegetais e 6,38 para proteínas lácteas). 
As concentrações protéicas reais ( $\mathrm{N}$ protéico $\mathrm{x} \mathrm{Fc}$ ) variaram entre 1,28 e 16,31 g/100 g de amostra e como era de se esperar, foram inferiores à concentração de proteína bruta. As diferenças corresponderam ao nitrogênio de origem não-protéica, que elevaram a concentração de $\mathrm{N}$ total dando origem a teores protéicos superestimados.

A legislação brasileira, como mencionado anteriormente, estabelece que a quantidade de proteína declarada no rótulo de alimentos embalados deve ser calculada a partir da multiplicação da concentração total de N, determinada pelo método de Kjeldahl, pelo fator de conversão $\mathrm{N}: \mathrm{P}$ correspondente, segundo o tipo de alimento em questão (Resolução RDC n. 360 de 23 de dezembro de 2003, da Anvisa).

A comparação entre as concentrações protéicas calculadas pelo $\mathrm{N}$ totalxFc e declaradas no rótulo e aquelas calculadas pelo $\mathrm{N}$ protéico $\mathrm{x} \mathrm{Fc}$ pode ser observada na Figura 1. Os valores de proteína bruta foram, na maioria das vezes, similares aos declarados no rótulo das sopas, indicando que os fabricantes determinaram a concentração protéica destes alimentos multiplicando o teor de $\mathrm{N}$ pelo fator conversão estabelecido pela legislação. As 22 amostras de sopas desidratadas apresentaram conteúdos protéicos brutos superiores às concentrações de proteína real, comprovando a presença de $\mathrm{N}$ de origem nãoprotéica.
A sopa de cebola (amostra $\left.\mathrm{n}^{\circ} 10\right)$ apresenta declarado em seu rótulo zero $\mathrm{g}$ de proteína/porção de sopa desidratada, atendendo ao "Regulamento Técnico sobre Rotulagem Nutricional de Alimentos Embalados" (Resolução RDC n. 360 de 23 de dezembro de 2003, da Anvisa) pela qual os alimentos cujas porções apresentarem quantidades de proteína inferiores que $0,5 \mathrm{~g}$, o conteúdo declarado no rótulo deverá ser zero. Contudo, a ingestão de quantidades maiores que uma porção poderá resultar em conteúdos protéicos diferentes de zero. Assim, apesar da rotulagem estar de acordo com a legislação vigente, a forma de arredondamento impossibilita o cálculo do teor real de proteína quando várias porções são consumidas. Este fato não acarreta prejuízo significativo à população sadia de um modo geral, porém, torna-se relevante para os pacientes fenilcetonúricos, que necessitam de informações exatas sobre o conteúdo protéico dos alimentos.

Grande parte dos alimentos industrializados apresenta em sua composição substâncias nitrogenadas nãoprotéicas na forma de realçadores de sabor, corantes, aromatizantes, entre outros. Esta é a grande problemática encontrada quando se estima Phe a partir do conteúdo protéico declarado no rótulo, uma vez que este nem sempre corresponde ao teor protéico real. Este fato é, muitas vezes, desconhecido por pais de crianças fenilcetonúricas e profissionais da área da nutrição.

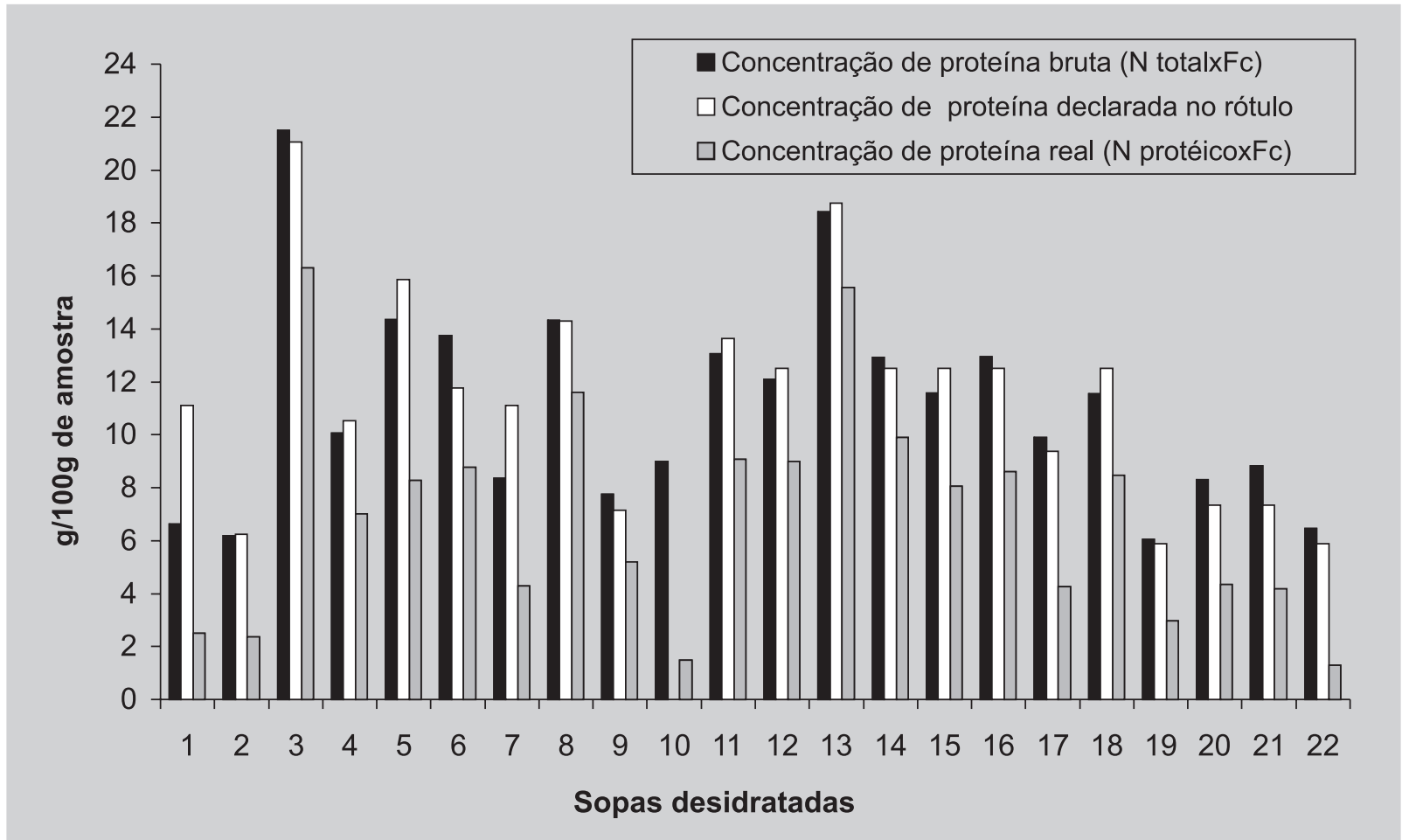

FIGURA 1 - Comparação entre a concentração de proteína bruta ( $\mathrm{N}$ total x Fc), declarada no rótulo e real ( $\mathrm{N}$ protéico x Fc) de sopas desidratadas instantâneas. 
Na Figura 2 é apresentada a distribuição percentual do nitrogênio protéico e nitrogênio não-protéico. Observase um perfil heterogêneo entre as sopas e uma contribuição variável, tanto do $\mathrm{N}$ protéico como do $\mathrm{N}$ não-protéico.

Sabe-se que elevado número de alimentos industrializados e mesmo alguns alimentos de origem vegetal contêm quantidades significativas de substâncias nitrogenadas não-protéicas das mais diferentes origens. As substâncias que podem contribuir para o aumento da concentração do $\mathrm{N}$ total em alimentos, em geral, são aminoácidos livres, pequenos peptídeos, ácidos nucléicos, corantes, quitina e sais inorgânicos como $\mathrm{NO}_{3}^{-}, \mathrm{NO}_{2}^{-}, \mathrm{NH}_{3}$ e $\mathrm{NH}_{4}^{+}$ (Hernández et al., 1995; Lucas et al., 1988; SaloVäänänen, Koivistoinen, 1996; Simonne et al., 1997; Sosulski, Imafidon, 1990; Tokoro et al., 1987; Yeoh, Truong, 1996).

Guimarães e Manfer-Marquez (2002) em estudo anterior com tabletes de caldo de carne verificaram que $95 \%$ do $\mathrm{N}$ presente neste tipo de alimento correspondia a $\mathrm{N}$ de origem não-protéica. A alta concentração de $\mathrm{N}$ não protéico era devida ao realçador de sabor glutamato monossódico, um ingrediente da formulação dos tabletes de caldos de carne.

Com o intuito de investigar as fontes de $\mathrm{N}$ não-protéico nas amostras de sopas desidratadas, foi determinada a con- centração de glutamato monossódico que parecia ser a fonte mais provável de $\mathrm{N}$ não-protéico. O glutamato monossódico é comumente utilizado em alimentos como realçador de sabor juntamente com pequenas quantidades de inosinato de sódio (IMP) e guanilato de sódio (GMP). Estes nucleotídeos são adicionados aos alimentos em baixas concentrações, tipicamente $0,01 \mathrm{~g} / 100 \mathrm{~g}$, e devido ao efeito sinérgico destes três realçadores de sabor, as quantidades de glutamato necessárias para dar sabor ao alimento, podem ser relativamente reduzidas. A contribuição do $\mathrm{N}$ proveniente do IMP e GMP é muito pequena e provavelmente não interfere de forma significativa na concentração de N total (Nguyen, Sporns, 1984; Duran-Merás et al., 1993).

A utilização do realçador de sabor glutamato monossódico é permitida pela Legislação Brasileira (Resolução RDC n. 1, de 2 de Janeiro de 2001, da Anvisa), não existindo um limite para a sua adição nos alimentos. A adição corresponde ao "quantum satis", ou seja, a quantidade necessária para dar o sabor desejado.

Na Tabela II, pode-se observar que a concentração de glutamato monossódico das sopas desidratadas variou entre 1,01 e 12,16 g/100 g de amostra. As sopas e cremes de cebola, com exceção do creme de cebola da marca Knorr, juntamente com o creme de galinha apresentaram as maiores concentrações de glutamato monossódico, com valo-

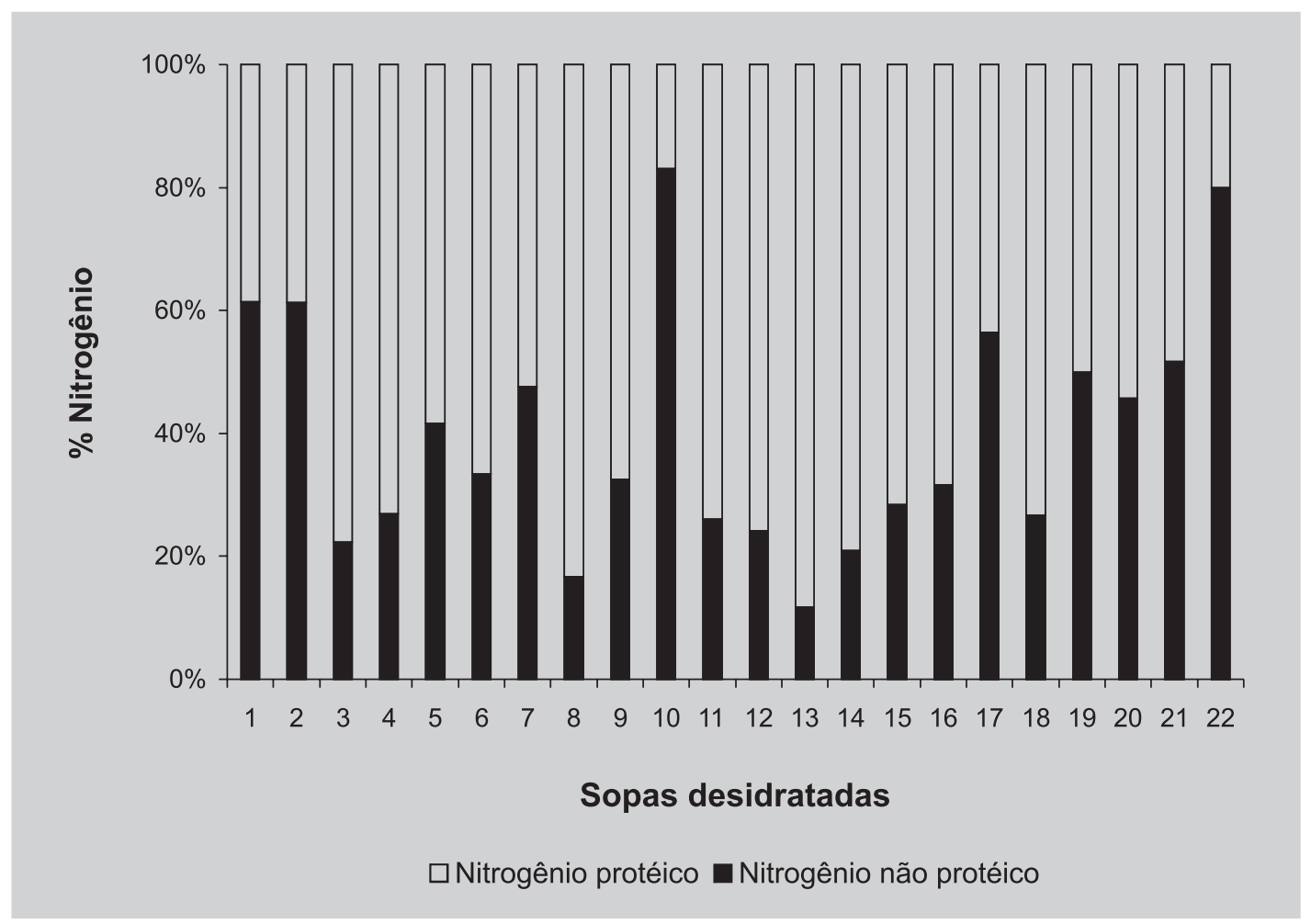

FIGURA 2 - Contribuição percentual de nitrogênio protéico e nitrogênio não-protéico em sopas desidratadas instantâneas. 
TABELA II - Concentração de glutamato monossódico (GMS) nas sopas desidratadas instantâneas

\section{Sopas}

GMS $^{1}$

g/100 g de amostra

(1) Creme batata c/ mandioquinha

$3,33 \pm 0,00$ (Knorr)

(2) Creme cebola (Knorr)

$3,78 \pm 0,06$

(3) Creme ervilha c/ bacon (Knorr)

$4,76 \pm 0,07$

(4) Creme milho verde (Knorr)

(5) Creme galinha (Maggi)

(6) Sopa carne c/ macarrão conchinha (Knorr)

(7) Creme Legumes (Knorr)

$3,04 \pm 0,06$

$12,16 \pm 0,07$

$4,25 \pm 0,07$

(8) Sopa galinha c/ fidelini (Knorr)

$3,74 \pm 0,07$

$2,42 \pm 0,00$

$4,45 \pm 0,07$

$7,86 \pm 0,00$

(10) Sopa cebola (Knorr)

(11) Creme queijo (Arisco)

$2,63 \pm 0,07$

(12) Sopão carne c/ macarrão e legumes (Knorr)

(13) Sopão feijão c/ macarrão e couve (Knorr)

(14) Sopão galinha c/ macarrão e legumes (Knorr)

(15) Canjão galinha c/ arroz e legumes (Knorr)

(16) Sopão carne c/ macarrão e legumes (Arisco)

(17) Canjão galinha c/ arroz e legumes (Arisco)

(18) Sopão galinha c/ macarrão e legumes (Arisco)

$3,45 \pm 0,07$

(19) Creme de cebola (Arisco)

(20) Creme de cebola (Maggi)

$3,77 \pm 0,00$

$6,59 \pm 0,06$

$6,91 \pm 0,00$

(21) Sopa de cebola (Maggi)

(22) Sopa de cebola (Arisco)

$6,90 \pm 0,00$ ma neste caso, uma vez que as sopas se destinam a uma faixa etária maior.

Foi calculada a contribuição do $\mathrm{N}$ proveniente do glutamato monossódico na concentração do $\mathrm{N}$ total e $\mathrm{N}$ não-protéico. Os resultados estão apresentados na Tabela III. O N proveniente do glutamato monossódico contribuiu com 2,53 a $45,15 \%$ na quantidade total de $\mathrm{N}$, ressaltandose que as sopas à base de cebola, creme de galinha e sopa de galinha com arroz apresentaram a maior contribuição, da ordem de 25,89 a 45,15\%. Na concentração de N nãoprotéico o $\mathrm{N}$ proveniente do glutamato monossódico contribuiu com 22,54 a 94,74\%, sendo que as sopas e cremes à base de cebola das marcas Maggi e Arisco, o creme de galinha e a sopa de galinha com arroz apresentaram maior contribuição, da ordem de 54,20 a 94,74\%. Nessa mesma tabela também é apresentada a concentração de $\mathrm{N}$ de origem não-protéica, que variou entre 0,33 e 1,27 g/100 g de amostra.

Estes resultados indicam que o glutamato monossódico não foi a única fonte de $\mathrm{N}$ não-protéico, acreditando-se que o restante era constituído, principalmente, por aminoácidos livres. Neste sentido, foi realizada leitura espectrofotométrica na solução sobrenadante resultante da precipitação ácida da proteína para verificar a eventual presença de Phe livre, que resultou negativa.

A estimativa da concentração de Phe nas sopas desidratadas foi feita a partir da concentração protéica real. Considerando que uma proteína tem, em média, $4 \%$ de Phe em sua composição (Bremer et al., 1996), as sopas desidratadas apresentaram concentração de Phe, que variou de 51,16 a $652,24 \mathrm{mg} / 100 \mathrm{~g}$ de sopa desidratada, como mostra a Tabela IV.

As amostras que mereceram destaque devido à baixa concentração de $P h e / 100 \mathrm{~g}$ foram as sopas e cremes à base de cebola e creme de batata com mandioquinha, com concentrações entre 59,16 e 173,16 mg Phe/100 g de sopa desidratada. Uma vez que a tolerância de ingestão de Phe na PKU clássica costuma situar-se ao redor de 250 a $350 \mathrm{mg}$ Phe/dia (Güttler, Guldberg, 1996), as sopas mencionadas representam contribuição muito útil na diversificação do cardápio de pacientes fenilcetonúricos, podendo ainda ser empregadas como matéria-prima para o preparo de cremes e molhos.

Assim, a utilização dos fatores de conversão N:P estabelecidos pela Legislação Brasileira só é válida para alimentos com reduzidos teores de N não-protéico. Nos alimentos em que isso ocorre, como é o caso das sopas desidratadas, há necessidade de extração prévia das substâncias nitrogenadas não-protéicas, para que a análise de $\mathrm{N}$ seja feita somente na fração protéica do alimento. tos infantis consumidos por criança com menos de 3 meses de idade (Walker, 1999), o que não representa um proble- 
TABELA III - Concentração de N não-protéico (NNP), em g/100g, e contribuição do nitrogênio proveniente do glutamato monossódico, na concentração do nitrogênio total (\%N-GMS NT) e na concentração do nitrogênio não-protéico (\%N-GMS NNP)

\begin{tabular}{lccc}
\hline Sopas & NNP $^{\mathbf{1}}$ & \%N-GMS NT $^{\mathbf{1}}$ & \%N-GMS NNP1 \\
\hline (1) Creme batata c/ mandioquinha (Knorr) & $0,70 \pm 0,02$ & $21,23 \pm 0,01$ & $34,88 \pm 0,01$ \\
(2) Creme cebola (Knorr) & $0,65 \pm 0,02$ & $25,89 \pm 0,44$ & $42,61 \pm 0,73$ \\
(3) Creme ervilha c/ bacon (Knorr) & $0,75 \pm 0,02$ & $10,13 \pm 0,14$ & $46,47 \pm 0,70$ \\
(4) Creme milho verde (Knorr) & $0,45 \pm 0,02$ & $12,71 \pm 0,27$ & $49,42 \pm 1,04$ \\
(5) Creme galinha (Maggi) & $0,94 \pm 0,04$ & $38,72 \pm 0,23$ & $94,74 \pm 0,56$ \\
(6) Sopa carne c/ macarrão conchinha (Knorr) & $0,70 \pm 0,04$ & $14,14 \pm 0,23$ & $44,43 \pm 0,74$ \\
(7) Creme Legumes (Knorr) & $0,68 \pm 0,04$ & $18,68 \pm 0,30$ & $40,10 \pm 0,65$ \\
(8) Sopa galinha c/ fidelini (Knorr) & $0,37 \pm 0,01$ & $7,73 \pm 0,01$ & $47,87 \pm 0,01$ \\
(9) Sopa galinha c/ arroz (Maggi) & $0,40 \pm 0,02$ & $26,29 \pm 0,41$ & $81,49 \pm 1,28$ \\
(10) Sopa cebola (Knorr) & $1,27 \pm 0,17$ & $36,90 \pm 0,01$ & $45,33 \pm 0,01$ \\
(11) Creme queijo (Arisco) & $0,50 \pm 0,04$ & $9,40 \pm 0,24$ & $38,54 \pm 0,99$ \\
(12) Sopão carne c/ macarrão e legumes (Knorr) & $0,46 \pm 0,01$ & $10,26 \pm 0,26$ & $43,26 \pm 1,12$ \\
(13) Sopão feijão c/ macarrão e couve (Knorr) & $0,33 \pm 0,01$ & $2,53 \pm 0,06$ & $22,54 \pm 0,56$ \\
(14) Sopão galinha c/ macarrão e legumes (Knorr) & $0,42 \pm 0,02$ & $9,84 \pm 0,24$ & $48,50 \pm 1,18$ \\
(15) Canjão galinha c/ arroz e legumes (Knorr) & $0,51 \pm 0,10$ & $11,59 \pm 0,27$ & $42,03 \pm 1,00$ \\
(16) Sopão carne c/ macarrão e legumes (Arisco) & $0,64 \pm 0,07$ & $14,03 \pm 0,01$ & $45,36 \pm 0,01$ \\
(17) Canjão galinha c/ arroz e legumes (Arisco) & $0,88 \pm 0,02$ & $13,15 \pm 0,01$ & $23,60 \pm 0,01$ \\
(18) Sopão galinha c/ macarrão e legumes (Arisco) & $0,49 \pm 0,08$ & $13,66 \pm 0,27$ & $51,57 \pm 1,00$ \\
(19) Creme de cebola (Arisco) & $0,51 \pm 0,02$ & $26,32 \pm 0,01$ & $54,20 \pm 0,01$ \\
(20) Creme de cebola (Maggi) & $0,63 \pm 0,01$ & $33,55 \pm 0,32$ & $76,69 \pm 0,73$ \\
(21) Sopa de cebola (Maggi) & $0,78 \pm 0,08$ & $33,09 \pm 0,01$ & $64,91 \pm 0,01$ \\
(22) Sopa de cebola (Arisco) & $0,88 \pm 0,08$ & $45,15 \pm 0,01$ & $57,46 \pm 0,07$ \\
\hline
\end{tabular}

${ }^{1}$ Valores expressos como média \pm desvio padrão $(\mathrm{n}=3)$.

TABELA IV - Concentração de fenilalanina (Phe), em mg/100 g de sopa desidratada

\begin{tabular}{lc}
\hline Sopas & mg Phe/100 g \\
\hline (1) Creme batata c/ mandioquinha (Knorr) & 100,40 \\
(2) Creme cebola (Knorr) & 94,44 \\
(3) Creme ervilha c/ bacon (Knorr) & 652,24 \\
(4) Creme milho verde (Knorr) & 281,00 \\
(5) Creme galinha (Maggi) & 331,08 \\
(6) Sopa carne c/ macarrão conchinha (Knorr) & 350,92 \\
(7) Creme Legumes (Knorr) & 172,04 \\
(8) Sopa galinha c/ fidelini (Knorr) & 463,84 \\
(9) Sopa galinha c/ arroz (Maggi) & 208,12 \\
(10) Sopa cebola (Knorr) & 59,16 \\
(11) Creme queijo (Arisco) & 362,56 \\
(12) Sopão carne c/ macarrão e legumes (Knorr) & 359,64 \\
(13) Sopão feijão c/ macarrão e couve (Knorr) & 622,08 \\
(14) Sopão galinha c/ macarrão e legumes (Knorr) & 396,40 \\
(15) Canjão galinha c/ arroz e legumes (Knorr) & 322,40 \\
(16) Sopão carne c/ macarrão e legumes (Arisco) & 344,32 \\
(17) Canjão galinha c/ arroz e legumes (Arisco) & 171,00 \\
(18) Sopão galinha c/ macarrão e legumes (Arisco) & 338,84 \\
(19) Creme de cebola (Arisco) & 118,24 \\
(20) Creme de cebola (Maggi) & 173,16 \\
(21) Sopa de cebola (Maggi) & 167,12 \\
(22) Sopa de cebola (Arisco) & 51,16 \\
\hline
\end{tabular}

\footnotetext{
${ }^{1}$ Para uma concentração de $4 \%$ de fenilalanina na proteína.
} 


\section{CONCLUSÕES}

O estudo da concentração protéica e fração nitrogenada não-protéica das 22 amostras de sopas desidratadas instantâneas permitiu concluir que a concentração de proteína bruta das sopas desidratadas determinada a partir da análise de $\mathrm{N}$ pelo método de Kjeldahl não representa o real conteúdo protéico presente. As concentrações de proteína bruta são até 5,2 vezes maiores que as concentrações protéicas reais, sendo possível comprovar a presença de $\mathrm{N}$ de origem não-protéica nas amostras de sopas desidratadas. As sopas desidratadas apresentam concentrações de glutamato monossódico variando entre 1,01 e 12,16 g/100 g de amostra, não tendo sido possível estabelecer padrão de adição de realçadores de sabor. $\mathrm{O} \mathrm{N}$ proveniente do glutamato monossódico contribuiu com 2,53 a 45,15\% na quantidade total de $\mathrm{N}$ e 22,54 a $94,74 \%$ na quantidade total de $\mathrm{N}$ não-protéico. As sopas desidratadas apresentam teores variáveis de Phe, variando entre 59,16 e 622,08 mg/100 g de sopa desidratada, sendo que as de menor valor constituem alternativa muito útil para a diversificação do cardápio diário de pacientes fenilcetonúricos, geralmente preparado à base de amido e vegetais.

\section{ABSTRACT}

\section{Estimation of phenylalanine (Phe) contents in dehydrated soups: significance of non-protein nitrogen}

The direct analysis of phenylalanine (Phe) in food with low protein content is difficult, time consuming and expensive. In general, more convenient indirect methods based on raw protein contents have been used, considering that natural proteins contain about $4 \%$ of Phe. In this paper the Phe contents of 22 commercial dehydrated soups were estimated taking into account the contents of total $N$, protein $N$ and non-protein nitrogen as well as the contents of monosodium glutamate (GMS) which were analyzed independently. The amounts of crude protein (total $N$ multiplied by an adequate conversion factor) ranged between 6.1 and $21.5 \mathrm{~g} / 100 \mathrm{~g}$, showing similarity with protein values on nutritional labels. The actual protein contents were significantly lower and Phe contents from these data varied between 51 and $651 \mathrm{mg} / 100 \mathrm{~g}$ sample. The GMS contents showed a significant contribution representing 2.5 to $42.7 \%$ of total $N$. In conclusion, due to the high contents of this flavor enhancer in some formulated soups, Phe should be estimated only after a previous extraction of non-protein nitrogen in order to avoid an overestimation of protein, and as a consequence, of Phe contents. Some dehydrated soups with low Phe contents had been found, creating the possibility to include them as an additional food choice for phenylketonurics.

UNITERMS: Phenylalanine. Phenylketonuria. Non protein nitrogen. Monosodium glutamate. Dehydrated soups.

\section{AGRADECIMENTOS}

Os autores agradecem à Ajinomoto Interamericana por disponibilizar equipamento para análise de GMS e ao apoio financeiro do Conselho Nacional de Desenvolvimento Científico e Tecnológico (CNPq).

\section{REFERÊNCIAS BIBLIOGRÁFICAS}

ACOSTA, P.B.; YANNICELLI, S.; MARRIAGE, B.; STEINER, R.; GAFFIELD, B.; ARNOLD, G.; LEWIS, V.; CHO, S.; BERSTEIN, L.; PARTON, P.; LESLIE, N.; KORSON, M. Protein status of infants with phenylketonuria undergoing nutrition management. J. Am. Coll. Nutr., New York, v.18, n.2, p.102-107, 1999.

ALMENDINGEN, K.; MELTZER, H.M.; PEDERSEN, J.I.; NILSEN, B.N.; ELLEKJAER, M. Near infrared spectroscopy: a potencially useful method for rapid determination of fat and protein content in homogenized diets. Eur. J. Clin. Nutr., Basingstoke, v.54, n.1, p.20-23, 2000.

ASSOCIATION OF OFFICIAL ANALYTICAL CHEMISTS. Official methods of analysis of the Association of Official Analytical Chemists. 16.ed. Arlington: AOAC, 1995. v.1.

BARRETO, W.J.; AQUINO, M.; ZAIA, D.A.M. A new method for total protein determination. Anal. Lett., New York, v.23, n.7, p.1279-1290, 1990.

BRASIL. Resolução - RDC n.1, de 2 de janeiro de 2001. A Agência Nacional de Vigilância Sanitária aprova o regulamento técnico que aprova o uso de aditivos com a função de realçadores de sabor, estabelecendo seus limites máximos para os alimentos. Diário Oficial da União, Brasília, 4 jan. 2001. Seção 1, p.21.

BRASIL. Resolução - RDC n.360, de 23 de dezembro de 2003. AAgência Nacional de Vigilância Sanitária aprova o regulamento técnico sobre rotulagem nutricional de alimentos embalados. Diário Oficial da União, Brasília, 26 dez. 2003. Seção 1. 
BREMER, H.J.; ANNINOS, A.; SCHULZ, B. Amino acid composition of food products used in the treatment of patients with disorders of the amino acid and protein metabolism. Eur. J. Pediatr., Berlin, v.155, suppl.1, p.S108-S114, 1996.

CHAMPE, P.C.; HARVEY, R.A. Metabolic defects in amino acid metabolism. In: Biochemistry. 2.ed. Philadelphia: J.B. Lippincott, 1994. p.253-255. (Lippincotts' illustrated reviews).

DANELL, E.; EAKER, D. Amino acid and total protein content of the edible mushroom Cantharellus cibarius (Fries). J. Sci. Food Agric., Bognor Regis, v.60, n.1, p.333-337, 1992.

DURÁN-MERÁS, I.; PEÑA, A.M.; ESPINOSAMANSILLA, A.; SALINAS, F. Multicomponent determination of flavor enhancers in food preparations by partial least squares and principal component regression modeling of spectrophotometric data. Analyst, Cambridge, v.118, n.7, p.807-813, 1993.

DUTRA, J.C.; WEIMER, T.A.; GIUGLIANI, R.; NETTO, C.A. Heterozygote detection in two hyperphenylalaninemia types: classic phenylketonuria nad dihydrobiopterin biosynthesis deficiency. Rev. Bras. Genet., Ribeirão Preto, v.9, p.123-131, 1986.

FREITAS, O.; IZUMI, C.; LARA, M.G.; GREENE, L.J. New approaches to the treatment of phenylketonuria. Nutr. Rev., New York, v.57, n.3, p.65-70, 1999.

GAINES, T.P. Determination of protein nitrogen in plants. $J$. AOAC Int., Gaithersburg, v.60, n.3, p.590-593., 1977.

GOLC-WONDRA, A.; SKOCIR, E.; PROSEK, M. Determination of monosodium glutamate in food products. J. Planar Chromatogr. - Mod. TLC, Budakalasz, v.8, n.1, p.117-121, 1995.

GUIMARÃES, C.P.; LANFER MARQUEZ, U.M. Composição química de tabletes de caldo de carne: nitrogênio protéico, não-protéico e fenilalanina. Cienc. Tecnol. Aliment., Campinas, v.22, n.3, p.308-313, 2002.

GÜTTLER, F.; GULDBERG, P. The influence of mutations on enzyme activity and phenylalanine tolerance in phenylalanine hydroxilase deficiency. Eur. J. Pediatr., Berlin, v.155, suppl.1, p.S6-S10, 1996.
HERNÁNDEZ, T.; CENTENO, C.; MARTÍNEZ, C.; HERNÁNDEZ, A. Effect of solvent extraction on the nitrogen compounds in alfafa protein concentrate. $J$. Agric. Food Chem., Columbus, v.43, n.5, p.3065-3069, 1995.

INSTITUTO ADOLFO LUTZ - IAL. Normas analíticas do Instituto Adolfo Lutz. 3.ed. São Paulo: Instituto Adolfo Lutz, 1985. 533p. (Volume 1, Métodos Químicos e Físicos para Análise de Alimentos).

JONES, D.B. Factors for converting percentages of nitrogen in foods and feeds into percentages of protein. U. S., Dep. Agric., Circ., Washington, v.183, p.1-21, 1931.

KRISHNAN, P.G.; PARK, W.J.; KEPHART, K.D.; REEVES, D.L.; YARROW, G.L. Measurement of protein and oil content of oat cultivars using near-infrared reflectance spectroscopy. Cereal Foods World, Saint Paul, v.39, n.2, p.105-108, 1994.

LANFER-MARQUEZ, U.M., PENTEADO, M. De V.C. Variação e nível de detalhamento de alguns nutrientes: teor de fenilalanina. Bol. Soc. Bras. Cienc. Tecnol. Aliment., Campinas, v.31, n.2, p.109-111, 1997.

LOURENÇO, S.O.; BARBARINO, E.; LANFER MARQUEZ, U.M.; AIDAR, E. Distribution of intracellular nitrogen in marine microalgae: basis for the calculation of specific nitrogen-to-protein conversion factors. J. Phycol., Malden, v.34, n.5, p.798-811, 1998.

LUCAS, B.; GUERRERO, A.; SIGALES, L.; SOTELO, A. True protein content and non protein amino acid present in legumes seeds. Nutr. Rep. Int., Stoneham, v.37, n.3, p.545-553, 1988.

MIRA, N.V.M.; LANFER MARQUEZ, U.M. Importância do diagnóstico e tratamento da fenilcetonúria. Rev. Saúde Pública, São Paulo, v.34, n.1, p.86-95, 2000.

MOSSÉ, J. Nitrogen to protein conversion factor for ten cereals and six legumes or oilseeds: a reappraisal of its definition and determination: variation according to species and to seed protein content. J. Agric. Food Chem., Columbus, v.38, n.1, p.18-24, 1990.

NGUYEN, T.T.; SPORNS, P. Liquid chromatographic determination of flavor enhancers and chloride in food. $J$. Assoc. Off. Anal. Chem., Washington, v.67, n.4, p.747751,1984 
NIKOLELIS, D.P. Kinetic - potenciometric determination of monosodium glutamate in soups and soups bases and of glutamic dehydrogenase. Analyst, Cambridge, v.112, p.763-765, 1987.

ROSENBERG, I.M. Protein analysis and purification: bentchtop techniques. Boston: Birkhäuser, 1996. p.130131.

SALO-VÄÄNÄNEN, P.P.; KOIVISTOINEN, P.E. Determination of protein in foods: comparison of net and crude protein (Nx6.25) values. Food Chem., Oxford, v.57, n.1, p.27-31, 1996.

SCHAUMBERG, H.H.; BYCK, R.; MASHMAN, J.H. Monossodium L-glutamate: its pharmacology and role in the Chinese restaurant syndrome. Science, Washington, v.163, p.826-828, 1969.

SIMONNE, A.H.; SIMONNE, E.H.; EITENMILLER, R.R.; MILLS, H.A.; CRESMAN, C.P. Could the Dumas method replace the Kjeldahl digestion for nitrogen and protein determinations in foods? J. Sci. Food Agric., Bognor Regis, v.73, n.1, p.39-45, 1997.

SOSULSKI, F.W.; IMAFIDON, G.I. Amino acid composition and nitrogen-to-protein conversion factors for animal and plant foods. J. Agric. Food Chem., Columbus, v.38, n.1, p.351-356, 1990.
STOCKCHEK, C.M. Quantification of protein. Methods Enzymol., San Diego, v.182, p.50-68, 1990.

TOKORO, N.; SAWADA, M.; SUGANUMA, Y.; MOCHIZUKI, M.; MASUZAWA, K.; AOYAMA, Y.; ASHIDA, K. Nitrogen composition of vegetables common to Japan. J. Food Compos. Anal., Amsterdam, v.1, p.18-25, 1987.

TSHINYANGU, K.K.; HENNEBERT, G.L. Protein and chitin nitrogen contents and protein content in Pleurotus ostreatus var. columbinus. Food Chem., Oxford, v.57, n.2, p.223-227, 1996.

WALKER, R. The significance of excursions above the ADI - case study: monosodium glutamate. Regul. Toxicol. Pharmacol., Orlando, v.30, p.S119-S121, 1999.

YEOH, H.-H.; TRUONG, V.-D. Protein contents, amino acid compositions and nitrogen-to-protein conversion factors for Cassava roots. J. Sci. Food Agric., Bognor Regis, v.70, p.51-54, 1996.

Recebido para publicação em 17 de agosto de 2004. Aceito para publicação em 21 de dezembro de 2004. 